\title{
A HEURÍSTICA DO MEDO EM HANS JONAS, À LUZ DA CONSTITUIÇÃO FEDERAL DE 1988
}

GLACIELLE BORGES TORQUATO 


\title{
A HEURÍSTICA DO MEDO EM HANS JONAS, À LUZ DA CONSTITUIÇÃO FEDERAL DE 1988
}

Recebimento: 01/08/2013

Aceite: 04/11/2013

Glacielle Borges Torquato ${ }^{1}$

\section{RESUMO}

A partir da leitura do princípio responsabilidade de Hans Jonas - com enfoque na heurística do medo - e da Constituição Federal - com a preservação ambiental intergeracional -, o presente estudo objetiva trazer reflexões acerca dos problemas éticos vivenciados na atualidade pela sociedade e as graves consequências advindas ao se ignorar os sinais externados pela natureza em virtude da tecnologia e capitalismo. A ideia é fazer um apelo à sociedade para que insira a responsabilidade como mote norteador de suas ações, notadamente quando do uso da técnica, valendo-se do agir consciente do poder, e possibilitando hoje ou no futuro distante, a liberdade do ser humano na busca por níveis de recursos naturais adequados à garantia da dignidade disciplinada no art. $1^{\circ}$, III, da Constituição Federal.

Palavras-Chave: Heurística do medo; Hans Jonas; Ética; Meio ambiente; Futuro.

\begin{abstract}
From the reading of the principle responsibility of Hans Jonas - focusing on the heuristics of fear - and the Constitution - with environmental preservation intergenerational -, this study aims to bring reflections on the ethical problems experienced by society today and the dire

1 Mestranda em Prestação Jurisdicional e Direitos Humanos pela Universidade Federal do Tocantins (UFT). Pós-Graduada em Gestão do Judiciário pela FAEL. Pós-Graduada em Direito Municipal pela UNIDERP. Graduada em Direito pela Universidade Federal do Tocantins (UFT). Analista Judiciário do Tribunal de Justiça do Estado do Tocantins e Chefe de Gabinete de Desembargador. E-mail: glacielletorquato@gmail.com.
\end{abstract}


consequences to ignore the signs externalized by nature in virtue of technology and capitalism. The idea is to appeal to society to insert the responsibility as a guiding motto of their actions, especially when the use of the technique, using the conscious act of power, and enabling today or in the distant future, the freedom of the human being in search for appropriate levels of resources to ensure the dignity disciplined in art. $1^{\mathrm{o}}$, III of the Constitution.

Keywords: Heuristics of fear; Hans Jonas; Etchis; Environment; Future.

\section{INTRODUÇÃO}

O desenvolvimento econômico e tecnológico da sociedade, fruto da Revolução Industrial do Século XVIII, potencializada pela expansão técnico-científica, teve o condão de impingir na humanidade uma reflexão até então tratada com absoluto desinteresse: a substancial degradação a que se viu submetido o meio ambiente em virtude desse crescimento não sustentável.

$\mathrm{O}$ incremento da incerteza relativamente às consequências das atividades tecnológicas empregadas no processo econômico era uma máxima do momento, intensificado pela crise ambiental do final da década de 60, fato que fez com que a sociedade voltasse sua atenção para o meio ambiente, ainda que fulcrada em interesses exclusivamente antropocêntricos. Porém fez exsurgir uma consciência até então inexistente, a de que os recursos naturais são finitos e merecem tratamento adequado. A utopia da abundância foi descortinada e trouxe consigo a consciência 
acerca da utilização responsável dos recursos naturais.

Nesse cenário absolutamente desolador e preocupante, Hans Jonas, filósofo judeu nascido em 1903 na Alemanha, publica o livro o princípio responsabilidade, propondo nova ética ao pensamento e comportamento humanos, cunhado numa premissa reflexiva acerca do destino do homem e da heurística do temor, por meio de um sentimento universal de responsabilidade ética ambiental.

O princípio responsabilidade, na visão do autor, passaria a abranger "um objeto de ordem inteiramente nova, nada menos do que a biosfera inteira do planeta acresceu-se àquele pelo qual temos de ser responsáveis....” (JONAS, 2006, p. 39).

$\mathrm{O}$ que pretendeu o filósofo foi reconhecer a vulnerabilidade da natureza diante das inovações tecnológicas, ao tempo em que externou preocupação com o círculo de ação não mais circunscrito à imediaticidade, mas às sequências de causa e efeito prolongadas no tempo.

Seguindo semelhante diretiva, a Constituição Federal de 1988 estabeleceu em seu artigo 225 a obrigatoriedade da preservação ambiental para a presentes e futuras gerações, destacando uma preocupação intergeracional que, até aquele momento histórico, era despida de normatividade.

O presente estudo objetiva, a partir da leitura do princípio responsabilidade de Hans Jonas - com enfoque na heurística do medo - e da Constituição Federal - com a preservação ambiental intergeracional -, trazer reflexões acerca dos problemas éticos vivenciados na atualidade pela sociedade e as graves 
consequências advindas ao se ignorar os sinais externados pela natureza em virtude da tecnologia e capitalismo.

\section{DESENVOLVIMENTO}

$\mathrm{O}$ direito à vida tem sua normativa assegurada historicamente nas Constituições Brasileiras, intitulado, por razões óbvias, como direito de indole fundamental.

No Documento Político Fundamental de 1988, por sua vez, é possível verificar substancial avanço, pois, a par de se resguardar a dignidade da pessoa humana, restou introduzido no texto constitucional o direito à sadia qualidade de vida. Conquanto sejam conceitos que certamente precisam de políticas públicas para serem dimensionados em sua completude, já têm seus alicerces fincados para o fim de se construir uma sociedade ecologicamente democrática e de direito.

O mesmo documento político mencionou, pela primeira vez em seu texto, a expressão "meio ambiente" e consignou, em seu art. 225, que "Todos têm direito ao meio ambiente ecologicamente equilibrado", sendo seguido, logo mais, pela consistente afirmação de ser ele "essencial à sadia qualidade de vida". Nesse momento, a Constituição Federal sinalizou de maneira induvidosa que a sobrevivência, com dignidade, não pode existir sem que, para tanto, se garanta um meio ambiente ecologicamente equilibrado.

Ao preceito constitucional são acrescidos seis parágrafos que impõem ao Poder Público deveres específicos a fim de 
lhes dar efetividade, sendo certo que o art. 225 deve ser lido conjuntamente com os princípios fundamentais inseridos dos arts. $1^{\circ}$ a $4^{\circ}$, que fazem da tutela ao meio ambiente um mecanismo de realização da cidadania e da dignidade da pessoa humana.

Sob tal enfoque, os direitos fundamentais, em especial o direito fundamental ao ambiente devem ser compreendidos como mecanismos de proteção que proporcionam garantias no sentido de se assegurar a defesa e a organização de bases adequadas e suficientes na construção dos níveis de qualidade de vida, no interesse da presentes e das futuras gerações, tal como definido pelo enunciado normativo do art. 225, caput, da CRFB.

Com efeito, por meio da base normativa contemplada pela Constituição Federal, conclui-se que o desenvolvimento de uma vida digna somente pode ser atingido com a proteção dos recursos naturais, fato que vincula a compreensão do significado de vida digna como referência inseparável dos objetivos de manutenção, conservação e melhoria da qualidade daqueles recursos da natureza.

Vislumbra-se clara redefinição ambiental do constitucionalismo, influenciado pelas experiências portuguesa (Constituição de 1976) e espanhola (Constituição de 1978). A primeira, em seu artigo 66, trouxe a definição de um modelo de proteção em que o meio ambiente representa direito fundamental atribuído a toda sociedade, exercendo, com tal premissa, grande influência sobre o artigo 225 da Constituição Brasileira.

Tais preceitos se justificam pela consciência, até então entorpecida, de que os recursos ambientais não são abundantes, 
tampouco infinitos.

Canotilho e Leite (2010, p. 44), sobre o assunto, afirmam que:

Antes, o meio ambiente não era tutelado, ou, se o era, não o era adequadamente ou para valer, exatamente porque a lógica do sistema jurídico alicerçava-se na falsa premissa da inesgotabilidade dos recursos naturais, totalmente negada pela poluição dos rios, do ar e do solo, e pela destruição acelerada da rica biodiversidade do país.

Complementam os autores afirmando que o novo olhar lançado à natureza e seus recursos "tem a ver com a imagem do passado, tanto disseminada, quanto equivocada, que insistia em compreender ou tratar o meio ambiente como uma entidade robusta e invencível, capaz de se autocurar continuamente."

Com efeito, conquanto a afirmação de um direito ao meio ambiente ecologicamente equilibrado traga como consectário lógico a dignidade da vida, não tem, por outro lado, o condão de definir o conteúdo do próprio direito fundamental ao ambiente como um direito à qualidade de vida ou à vida digna. Esta pode ser compreendida, em ambas as leituras, como um efeito que resulta indescuravelmente do principal objetivo garantido e assegurado pela norma de direito fundamental: a proteção dos recursos naturais.

Sob tal viés, o direito ao meio ambiente ecologicamente equilibrado tem por razão de existir a garantia à proteção subjetiva da liberdade de acesso à qualidade dos próprios recursos 
naturais, valendo o registro de que a liberdade, aí compreendida, importa na possibilidade de se usufruir de cada um dos recursos, os quais não podem ser obstados por quaisquer tipos de ações potencialmente perigosas, sejam públicas ou privadas, que venham a comprometer aqueles níveis de qualidade ambiental.

Dessa maneira, mesmo que tenha definido uma orientação antropocêntrica, não se pode deixar de admitir que o âmbito de proteção da norma de direito fundamental circunscreve não apenas à vida humana, mas aos próprios recursos naturais, enquanto objetos de gozo e fruição, sendo a qualidade de tais recursos o objeto de proteção do direito fundamental.

Gomes (2000, p. 3-4) nos conclama à reflexão ao questionar o quid a ser colocado sob análise do direito "ou seja, saber o que se vai tutelar, e como, depende de uma opção ideológica que reside em saber se o que se pretende é salvaguardar a natureza enquanto bem em si mesma".

Um aspecto relevante com relação à efetividade da proteção do meio ambiente para a presentes e futuras gerações é o reconhecimento de que o seu caminho passa necessariamente pela estrada da ética, cuja significação, nas palavras de Bittar (2013, p. 25), "corresponde ao exercício social da reciprocidade, respeito e responsabilidade."

A razão vem abordada com suficiente clareza e lucidez por Hans Jonas quando traça um novo imperativo, por meio do qual "podemos arriscar a nossa própria vida (...) mas não temos o direito de escolher a não-existência de futuras gerações em função da existência da atual, ou mesmo de as colocar em 
risco." (2006, p. 48). Sob tal enfoque, até mesmo a ideia da reciprocidade, na ética, passa a não mais ser relevante, pois a perspectiva intergeracional não permite uma correspondência imediata da ação e respectiva correspondência.

Com tais considerações, o filósofo deixou registrada uma proposta ética para a geração tecnológica, capaz de reconhecer e salvaguardar o meio ambiente como direito autônomo. Isso porque, embora reconhecida a dificuldade de se impor limites jurídicos e até mesmo éticos ao processo de desenvolvimento tecnológico, é a incapacidade de previsibilidade dos efeitos destrutivos dessa dinâmica do crescimento que imporá essa nova conscientização.

No caminho trilhado, como se pode perceber, o temor e incerteza sobre o futuro é a primeira das preocupações lançadas pelo autor por meio da ética da responsabilidade, pois obriga o ser humano a refletir sobre o seu comportamento atual e eventuais efeitos deletérios passíveis de advir às gerações futuras com tais ações, notadamente no que concerne à liberdade de escolha dos níveis de recursos naturais imprescindíveis à sobrevivência com dignidade.

A supracitada responsabilidade intergeracional, sob a perspectiva da heurística do medo, pode ser retratada da seguinte maneira:

(...) é como o de um avião no meio da neblina, sem mapas ou instrumentos. Em vez de serem capazes de gerar um sistema confiável de radar, nossos cientistas estão espiando pela janela da cabine tentando nos avisar sobre os obstáculos que temos à frente. E, normalmente, 
o melhor que eles estão podendo fazer é informar que a massa escura que está entrando no nosso campo de visão pode ser uma barreira de nuvens. OU, quem sabe, uma montanha. (CORBORN e outros, 2002, p. 276)

Zancanaro (1998, p. 57), sobre o assunto, esclarece que:

\begin{abstract}
A heurística do temor não é seguramente a última palavra na busca do bem, mas, um veículo extraordinariamente útil. Deveria ser aproveitada para o empreendimento de preservação do planeta, podendo, dessa forma, acordar para a possibilidade de uma catástrofe, assim provocando a necessidade do limite e da renúncia em relação ao uso de certas tecnologias. O medo seria uma forma de frear a compulsão e a onipotência prometeana de considerar o conhecimento científico ilimitado.
\end{abstract}

Cuida-se de opção ética pela previsibilidade negativa acerca do futuro, como catástrofes, extinção de espécies, raças e demais calamidades, cunhadas pelo comportamento humano da atualidade. A antecipação do cenário fundando no mau prognóstico acarreta o medo e este é utilizado para frear a atitude destruidora do ser humano perante a natureza.

É, sem dúvida, um passo significativo para o comportamento cauteloso do ser humano, assim como para a releitura do princípio ético dirigido não apenas para aqueles atingidos pela ação imediata, mas também para os homens do futuro. Permitir uma existência digna para estes é dever ético inescusável e inegociável.

Não se pode deixar de esclarecer, por certo, as polêmicas havidas com a teoria do "mau prognóstico", pois poderiam ter 
o efeito inverso do pretendido, amparado na premissa de que se tudo vai ter um fim, não faz sentido implementar mudanças ou mesmo trazer a ideia de que o perigo externado é tão exagerado que não se avilta a possibilidade de efetivamente ocorrer.

Contudo, apesar das teses adversas, a heurística do medo jonasiana, nas palavras de Oliveira (2011):

é um antídoto contra as profecias de salvação (muitas vezes anunciadas, hoje em dia, pela boca daqueles que esperam da ciência, mais uma vez, uma solução milagrosa para os problemas ambientais que nos afetam, enquanto cruzam os braços para atitudes urgentes que indiquem a responsabilidade com o meio ambiente) e não um pessimismo em relação ao futuro.

$\mathrm{O}$ antropocentrismo e reducionismo kantiano, fundando no domínio da natureza pelo ser humano e recusa de qualquer saber que revelasse autonomia aos recursos naturais, passou a não mais atender as pretensões éticas e morais de efeitos mediatos, fato que resultou na proposição, por Hans Jonas, de um novo imperativo, mais adequado à realidade enfrentada pela sociedade contemporânea: "Aja de modo a que os efeitos da tua ação sejam compatíveis com a permanência de uma autêntica vida humana sobre a Terra", em substituição à clássica de Kant, que dizia: "Aja de modo que tu também possas querer que tua máxima se torne lei geral" (2006, p. 47-48).

Assim, considerando-se que a ética "encontra na mais robusta fonte de inquietações humanas, o alento para sua existência", traduzindo-se como "o fino equilíbrio sobre a 
modulação e a dosagem dos comportamentos no plano da ação humana" (Bittar, 2013, p. 25), é de se admitir que o apelo sensível no que concerne à dignidade da pessoa e à inviolabilidade do direito à vida garantirão o despertar dessa nova consciência pautada no reconhecimento de um direito fundamental à proteção e promoção do ambiente, numa perspectiva intergeracional jonasiana como pressuposto lógico à efetivação daqueles direitos.

\section{CONSIDERAÇÕES FINAIS}

O progressivo quadro de degradação a que o meio ambiente tem sido submetido, notadamente após a Revolução Industrial do Século XVIII, levou a humanidade a lançar um novo olhar para os recursos naturais, que ascenderam ao posto de direitos fundamentais de terceira dimensão, incorporados nos textos constitucionais dos Estados Democráticos de Direito.

$\mathrm{Na}$ CRFB, de 1988, não foi diferente. Foi dispensado um capítulo inteiro ao meio ambiente, alçando-o à categoria de bem protegido constitucionalmente. É que o reconhecimento do direito a um meio ambiente de qualidade e sadio traduz-se como inquestionável extensão do direito à vida, seja sob a perspectiva da existência física e saudável dos seres humanos, seja sob o aspecto da dignidade dessa existência.

Com efeito, não basta simplesmente viver ou conservar/ garantir o direito à vida. É necessário atingir níveis suficientes de qualidade de vida, os quais somente poderão ser atingidos 
com a preservação dos recursos naturais, únicos com potencial de garantir e conservar a evolução da humanidade, numa perspectiva intergeracional, inspirada no princípio responsabilidade, de Hans Jonas e na própria Constituição Federal, com a disciplina do art. 225.

O que se propõe, num primeiro momento, é a promoção de uma conduta ética de reflexão sobre as atitudes presentes, pautada pelo prognóstico do medo do porvir, que deverá ascender para atitudes práticas e efetivas na luta por um meio ambiente equilibrado e saudável. Esse caminho passa essencialmente pela valorização do meio ambiente e pela atenção e prudência não apenas com reparação e repressão dos danos ambientais, mas principalmente com a prevenção, exigindo das pessoas comportamento condizentes ao respeito que todos necessitam ter com os seus semelhantes (ainda que do futuro) e com o próprio meio ambiente.

Com base na teoria apresentada por Hans Jonas, o afã pelo desenvolvimento tecnológico deve ser temperado pela expressão cunhada na heurística do medo, que elucida de maneira sensata, ainda que sob o viés hipotético, as possíveis consequências advindas desse crescimento desenfreado para a sobrevivência do ser humano e para a própria qualidade dessa sobrevivência.

Sua proposta pode ser traduzida, em breves linhas, como um apelo para que a sociedade insira a responsabilidade como mote norteador de suas ações, notadamente quando do uso da técnica, valendo-se do agir consciente do poder, e possibilitando 
hoje ou no futuro distante, a liberdade do ser humano na busca por níveis de recursos naturais adequados à garantia da dignidade estatuída pelo art. $1^{\circ}$, III da Constituição Federal.

O princípio da precaução, cunhado na heurística do medo de Hans Jonas, e o da cooperação é que vão garantir a própria existência humana na Terra, sendo certo que inexiste outra exigência mais urgente para a ética do que a própria vida.

Aperspectiva intergeracional imputada ao comportamento humano e lançada ainda na década de 70, tem o condão de alertar a sociedade contemporânea para a necessidade de escolha acerca da possibilidade de existir, daquilo que se pretende ser e até mesmo do mundo em que se almeja viver. A ética, nessa seara reflexiva, é que será capaz de impingir a sensatez nesse direito de escolha.

\section{REFERÊNCIAS}

BITTAR, Eduardo C. B. Curso de Ética Jurídica: ética geral e profissional. 10 ed. rev. atual. e modificado. São Paulo: Saraiva, 2013.

BRASIL (1988). Constituição da República Federativa do Brasil de 1988. Presidência da República, Casa Civil, Subchefia para Assuntos Jurídicos, Brasília. Disponível em <http://www. planalto.gov.br/ccivil_03/constituicao/constitui\%C3\%A7ao. htm>. Acesso em: 01 jul 2013. 
CANOTILHO, José Joaquim Gomes; LEITE, José Rubens Morato. Direito constitucional ambiental brasileiro. 3 ed. São Paulo: Saraiva, 2010.

CANOTILHO, José Joaquim Gomes; MOREIRA, Vital. Fundamentos da Constituição. Coimbra: Coimbra Editora, 1991.

CORBORN, Theo; DUMANOSKI, Dianne; MYERS, John Peterson. O futuro roubado. Porto Alegre: L\&M, 2002.

\section{ZANCANARO, Lourenço. O Conceito de Responsabilidade} em Hans Jonas. Tese de Doutoramento em Educação. Campinas: Universidade Estadual de Campinas. 1998. 230 p.

OLIVEIRA, Jelson Roberto de. A heurística do temor e o despertar da responsabilidade. Entrevista fornecida à Revista do Instituto Humanitas Unisinos. Disponível em < http://www.ihuonline.unisinos.br/index.php?option=com content $\&$ view $=$ article $\& i d=4035 \&$ secao $=371>$. Acesso em: 15 jul 2013.

JONAS, Hans. O Princípio Responsabilidade: ensaio de uma ética para uma civilização tecnológica. Rio de Janeiro: PUC Rio, 2006. 
GOMES, Carla Amado. O ambiente como objecto e os objectos do direito do ambiente. Este texto corresponde, no essencial, à exposição oral da autora, subordinada ao mesmo título, no Curso de Pós-Graduação em Ciências Jurídico-Administrativas da Faculdade de Direito de Lisboa. 